\title{
Expiration day effects on European trading volumes
}

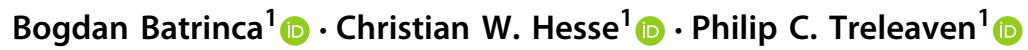

Received: 25 July 2016 / Accepted: 18 October 2018 / Published online: 22 January 2019

(C) The Author(s) 2019

\begin{abstract}
This study investigates the effect of periodic events, such as the stock index futures and options expiration days and the Morgan Stanley Capital International (MSCI) quarterly index reviews, on the trading volume in the pan-European equity markets. The motivation of this study stems from anecdotal evidence of increased trading volume in the equity markets during the run-up to the index options and futures expiration days and MSCI rebalances. This study investigates this phenomenon in more detail and analyses the trading volumes of seven European stock indices and the MSCI International Pan-Euro Price Index. The analysis features a multi-step ahead volume forecast, which is important for practitioners in order to plan multi-day trades while looking to minimise the market impact. The results confirm higher trading activity on the futures and options expiration days, as well as on the MSCI rebalance day. We report a clear futures and options expiration day effect, which accounts for the Friday effect in terms of larger trading volumes. The MSCI rebalance trading volume is significantly different from the volume of the adjacent months with no MSCI reviews, but they cannot explain the end-of-month effect entirely.
\end{abstract}

Keywords Trading volume $\cdot$ Expiration day effect $\cdot$ Behavioural finance $\cdot$ European stock market $\cdot$ Feature selection

JEL Classification C32 • C52 · C58 · G12 · G15 • G17

Bogdan Batrinca

bogdan.batrinca.09@ucl.ac.uk

Christian W. Hesse

c.hesse@ucl.ac.uk

Philip C. Treleaven

p.treleaven@ucl.ac.uk

1 Department of Computer Science, University College London, Gower Street, London WC1E 6BT, UK 


\section{Introduction}

This study investigates the increased trading volume associated with recurring special events, namely the stock index futures and options expiration days and the MSCI quarterly index reviews; this is known as 'the expiration day effect' in the literature. We analyse a number of aspects related to the expiration dates, such as the existence of an anticipatory/reactive expiration day effect (i.e. whether the volumes are higher during the days leading up to and following the MSCI rebalances and the stock index options and futures expiration days) and the identification of the principal volume drivers of this phenomenon. The study aims to distinguish between the index options and futures expiration day effects being examined in this study and well-established calendar effects, such as the Friday effect or the end-of-month effect. We discriminate between the Friday effect and the stock index options and futures expiration days, and between the end-of-month effect and the MSCI quarterly reviews in order to identify the primary drivers of increased trading activity.

Typically, financial markets are in a steady state, but they start fluctuating when certain events occur, e.g. company annual reports and announcements, news events, or other (periodic) calendar events, such as the subject of this study (i.e. the expiration days and rebalances). We explore activity surges around the stock index options and futures expiration days and MSCI quarterly reviews.

The contribution of this study is threefold: first, the expiration day effect has been scarcely investigated in the literature, and, out of this small proportion, there is a very small number of papers employing data from the European markets; second, the majority of this specialised literature focuses on returns, while the volume dimension is mostly ignored; and third, planning multi-day trades is important to practitioners and we propose a multi-step ahead prediction model for the expiration day effect. As far as we are aware, this is the first pan-European study on index options and futures expiration days and MSCI rebalances, while employing the most recent 15 years of daily market data.

The aim of this study is to provide a trading volume in-sample analysis while considering aspects such as the futures and options expiration days and the MSCI quarterly index reviews. The expiration days are an instance of a sparse event and we investigate the futures and options expiration days for 7 of the most liquid European stock indices. The study deals with a set of data analysis challenges and investigates a phenomenon whose scope is new. We propose a novel methodological approach in finance by manually constructing the expiration day calendar data set for the most liquid European indices, retrieving the daily market data for the historical constituents for a 15-year period, rigorously testing the existence of the expiration day effect, and ultimately applying stepwise regression. We inspect anticipatory and reactive effects of the index expiration days and review dates by analysing the previous and following five business days relative to the expiration days. The expiration days consist of all dates when the index options and futures stop trading for a given index.

The study proceeds as follows: Sect. 2 surveys the relevant literature on calendar effects, including the expiration day effect, the Friday effect, and the end-of-month effect, along with a succinct review of the volume-price relation, the stock index futures and options expiration days, and MSCI rebalances; Sect. 3 describes the data sample 
being investigated, such as the stock universe and the calendar data, while also providing summary statistics on the magnitude of the expiration day effect one week before and after the expiration day and the quarterly review date; Sect. 4 introduces our analytical approach, and the methodology of this experiment; Sect. 5 explores a potential relationship between trading volume and index options and futures expiration days and MSCI rebalances based on OLS descriptive models; following this exploratory analysis, Sect. 6 tests the existence of the investigated effects by conducting randomisation tests, while Sect. 7 introduces and explains the results of the stepwise regression predictive models fit for the index expiration day and MSCI rebalance analyses; finally, Sect. 8 concludes the study with a discussion on the main findings.

\section{Background}

This section starts with a survey of some of the relevant calendar effects, in order to understand the seasonal market dynamics that have been empirically identified as potential drivers of volume or price returns. This is followed by a short review of the relation between trading volume and price returns, and an introduction to stock index futures and options, potential mechanisms behind the increased trading volume around the futures and options expiration days, and MSCI index reviews.

\subsection{Calendar effects}

The majority of the literature on calendar effects looks at the relation between calendar anomalies and price returns, while the relation with the trading volume is barely covered. We start by reviewing the relevant calendar effects and then we outline the empirical findings on the connection between volume and price, in order to infer the calendar effects and their impact on trading volume.

Calendar effects are essentially anomalies in the financial markets that are associated with the calendar seasonality. The literature on calendar effects (and on behavioural finance, in general) is highly contentious and its empirical findings are usually inconclusive. One of the reasons is that each calendar effect is usually investigated in isolation, while a full universe of calendar effects would diminish the effect size of the calendar anomalies (Sullivan et al. 2001). It is worth mentioning that the calendar effects have always been identified ex post due to their dependence on empirical evidence from the past time series supporting their existence. The dynamics of some calendar effects is also known to change or reverse over time (Dimson and Marsh 1999; Schwert 2003; Hansen et al. 2005; Pearce 1996), while other calendar effects tend to persist through time, as reported by Lakonishok and Smidt (1988), Barone (1990), Agrawal and Tandon (1994), and Mills and Coutts (1995). The following review of calendar effects outlines some of the event-driven irregularities markets experience.

\subsubsection{Weekend effect and the Friday effect}

The weekend effect consists of a negative weekend return, implying that the Friday returns are greater than the returns on the following Monday. This calendar anomaly 
has been widely studied in the literature by authors such as French (1980), Gibbons and Hess (1981), Jaffe and Westerfield (1985), Pettengill (2003), or Cross (1973). Based on the correlation between price and volume that will be introduced in this section, we investigate the 'Friday effect' in conjunction with the expiration day effect because the stock index futures and options expiration days typically fall on the third Friday of the expiration months, and both effects are associated with increased trading volume.

\subsubsection{Expiration day effect}

The expiration day anomaly consists of higher trading volume and abnormal volatility near the close on expiration days (Stoll and Whaley 1997; Sukumar and Cimino 2012; Chow et al. 2003; Sadath and Kamaiah 2011). This is particularly of interest to this research, as we investigate the trading volume's relationship to the MSCI rebalances and index options and futures expiration days. Pope and Yadav (1992) found an immediate increase in trading volume before the options expiration day on London Stock Exchange, followed by an immediate decrease after the expiration day. Using Indian financial data, Vipul (2005) observed an abnormally high trading volume, which starts to increase on the previous day of the expiration day and continues into the next day for stocks with relatively high volume of derivatives. Chakrabarti et al. (2005) investigate the effects of changes in MSCI indices and find that the trading volume increases significantly and remains high after the change date for the stocks added to the index. Furthermore, Chiang (2009) observed trading volume peaks occurring on the third Friday of each month; this effect is driven by the option expiration day, since it appears only among optionable stocks, with options expiring on the third Friday of the month.

\subsubsection{Turn-of-the-month and end-of-month effects}

Another popular effect is the turn-of-the-month effect or end-of-month effect, including other similar effects such as the intra-month, the week-of-the-month and the monthly effects. The intra-month effect consists of positive returns in the first half of the month (and more specifically in the early days of the calendar months) only (Ariel 1987; Rosenberg 2004). The turn-of-the-month effect (Cadsby and Ratner 1992) has been typically defined as the stock price surge on the last day of one month and the first three days of the next month. The four-day turn-of-month period represents $87 \%$ of the average monthly return (Kunkel et al. 2003). A plausible explanation is the standardisation of payments at the turn of the month (Ogden 1990). Investigating thinly traded Finnish stocks, Nikkinen et al. (2009) found that the release of major US macroeconomic news is driving the turn-of-the-month and intra-month anomalies. Moreover, the higher returns at the turn-of-the-month are associated with a surge in trading volume, which is potentially caused by the buying pressure at the end of the month (Booth et al. 2001). Strong effects on volume are found in the last trading week of the month in the Finish stock index futures, options, and cash markets (Martikainen et al. 1995). 


\subsection{The volume-price relation}

The empirical evidence from the literature broadly supports the positive correlation between volume and price changes (Harris and Raviv 1993; Hong and Stein 2007). The articles on the price-volume relation reported two forms of price indicators that are correlated with trading volume: first, the magnitude (or absolute value) of the price change, i.e. $|\Delta p|$ (Assogbavi and Osagie 2006); second, the price change per se (or the raw price change value), i.e. $\Delta p$ (Karpoff 1987). The price change can be either the log-price difference or the percentage price change.

\subsection{Stock index futures expiration}

Stock index futures were introduced in 1982 and are the second most widely traded futures markets by investors, after interest rates (CME Group 2013). They consist of a prediction of where the underlying index cash market will be and introduced the concept of a cash settlement mechanism in order to address the problem of logistical difficulties regarding the delivery of the actual stocks associated with a particular stock index. A stock index tracks the changes in value of a hypothetical portfolio of stocks. More precisely, a stock's weight in the portfolio represents the proportion of the portfolio that is invested in the stock (Hull 2002). When investors engage in a futures contract, they buy the exposure. Entering a futures contract is done synthetically; people are not buying or trading the underlying basket of stocks. Therefore, a future contract can be regarded as a financial position, where buyers and sellers settle in the currency associated with the investment, since the index comprises of stocks from many companies and their ownership cannot be transitioned at settlement.

The futures expiration days represent the dates when the futures contracts stop trading and when the final price settlement occurs. The expiration days for the investigated European stock index futures occur on the third Friday of the expiration month or the previous day in case this is a bank holiday. The indices' futures contracts are traded either on a quarterly basis, i.e. March, June, September and December (e.g. FTSE 100 and DAX 30), or monthly (e.g. CAC 40, FTSE MIB, IBEX, Amsterdam Exchange, and OMX Stockholm 30). There are two broad categories of players in the futures market, namely hedgers, who are protecting against price risks, and speculators, who seek profits from the price changes that hedgers are protecting against.

\subsection{Stock index options expiration}

Index options are financial derivatives giving the holder the right, but not the obligation, to buy or sell the value of an underlying index, such as the FTSE 100, at the stated exercise price on the expiration day of the option for the European style index options or at any time before the expiration day for American style index options. There are no actual stocks being bought or sold; index options are always cash-settled. Chicago Board Options Exchange (CBOE) has been offering cash-settled options on stock indices since 1983 (CBOE 2015). 
Apart from potentially profiting from general index level movements, index options can be employed to diversify a portfolio when an investor prefers not to invest directly in the underlying stocks of the index. Index options can also be used in multiple ways in order to hedge specific risks in a portfolio.

The delta of an option is the option price rate of change relative to the price of the underlying asset; it is the slope of the curve relating the option price to the underlying asset price (Hull 2002). Delta hedging is an option strategy aiming to hedge the risk associated with price fluctuations in the underlying asset of the options contract by offsetting long and short positions. The investor's position remains delta hedged (or delta neutral) only for a relatively short period of time since delta changes. Therefore, the hedge has to be adjusted periodically, which is known as rebalancing.

\subsection{Possible mechanisms behind increased trading activity around expiration dates}

The effect of volume surges around index options and futures expiration days and MSCI rebalances can be driven by a number of potential mechanisms, such as the roll forward procedure or the rebalancing of delta hedges.

A potential explanation of the larger trading volumes before the stock index futures expiration day consists of investors wanting to roll their futures contracts. Index options and futures expire and need to be rolled into the new expiration. Investors are going to maintain the position beyond the date and they have to exchange their contract for the next contract (i.e. rolling the position) when the contract expires by placing a trade in another futures or options contract with an expiration day that is further in the future. A roll forward enables traders to maintain their position beyond the initial expiration of the options or futures contract. The roll forward is usually carried out shortly before the expiration day of the initial contract and requires the settlement of any gains or losses on the original contract. Most of the futures contracts are not held until the expiration day. Typically, short-term traders exit their futures positions before their expiration day in order to avoid physically buying or selling the underlying product. However, some close their positions in the run-up to the expiration. There are also mechanisms such as ETFs (i.e. exchange-traded funds) that are tracking indices.

Generally, volume surges in the run-up to expiration days, which leads to an increase in volatility, which then spills over to the equity markets (temporary departures from the fair value of the index futures and options than the actual basket of stocks).

Exchange-based trading of options was introduced on the Chicago Board Options Exchange (CBOE) in the USA in 1973, initially as a pilot program. The main reason for this incremental adoption of option trading was the concern that underlying stock prices could be affected by the exchange-listed option trading. However, little evidence has been published to validate the impact of option trading on underlying stock prices until CBOE (1975) publishes an early report concluding that there is no evidence of abnormal price behaviour in the run-up to the option expiration day.

More recently, Ni et al. (2005) provide evidence that option trading impacts the prices of underlying stocks and that the closing prices of optionable stocks cluster at option strike prices on expiration dates. The average alteration of the returns of 
stocks with listed options is at least 16.5 basis points per expiration date. According to $\mathrm{Ni}$, Pearson and Poteshman, the key drivers of stock price clustering are delta-hedge rebalancing by option market makers with net purchased option positions, described by Avellaneda and Lipkin (2003), and stock price manipulation by option writers, who write options in the week leading up to the option expiration.

Option pinning is the tendency of stock prices to finish near a strike price on the option expiration days. It involves two markets (i.e. the option market and the underlying asset market), while extending to many other interrelated derivative markets for a given index, e.g. futures on the index, options on the futures, options on the index etc. This phenomenon has been studied by Golez and Jackwerth (2012), who argue that index options induce pinning in the market for index futures. The economic mechanism driving the index futures pinning consist of the interplay of market makers, who rebalance their delta hedge as a result of the time decay of those hedges and as a response to reselling and early exercise of in the money (ITM) options by individual investors.

All in all, option market makers absorb excess demand as options are in zero-net supply and market makers typically hedge their exposure by trading the underlying asset. When options are approaching the expiration day, delta can rapidly change and trigger frequent adjustment of delta hedges, leading to an increased volume in the underlying asset.

\subsection{MSCl quarterly index review}

The Morgan Stanley Capital International (MSCI) indices group is an investment decision support provider and its indices have been tracked closely by international fund managers since 1969. Approximately $\$ 8$ trillion are estimated to be benchmarked to the MSCI indices worldwide (MSCI 2014) and 97 of the top 100 largest asset managers are served by MSCI (MSCI 2015). Any stock addition or deletion in any MSCI index attracts significant investor attention across the world. In order to reflect the evolving market, the MSCI indices constituent list changes on a quarterly basis, in February, May, August and November, close to the last trading day of these four rebalancing months. The MSCI national indices' changes are announced two weeks prior to the effective date, allowing the investors to react to the MSCI announcements.

The main objective of index funds is to replicate the performance of a given benchmark. Fund managers need to provide the lowest costs and high transparency to their clients, i.e. equity investors, and are more likely to minimise the benchmark tracking error than to take risks for increasing the returns. MSCI index rebalancing revision schedules are publicly released well before the effective revision date, giving rise to speculations. There are clear abnormal returns around the announcement and implementation dates of the MSCI reviews, with a high concentration in the preceding trading days to implementation. This is followed by reversal after the implementation date. Most importantly, the MSCI abnormal returns were correlated with the trading volume, concluding that the majority of fund managers re-adjust their portfolios at the last minute in order to minimise the tracking error. For the additions and deletions 
of the MSCI review, the trading volume was on average four times higher on the implementation day than on normal trading days (The Trade 2007).

\section{Data set}

The sample data set covers 7 liquid European indices and the MSCI International Pan Euro Price Index, between 1st January 2000 and 10th May 2015. The stock universe includes a sample of 506 unique stocks, out of which 408 are members of the indices considered for the stock index expiration day analysis and 344 are constituents of the MSCI International Pan Euro Price Index. The daily market data is complemented by a series of special events, which are potentially associated with non-stationarity. We manually collected expiration dates for the stock index futures and options across 7 European indices and the MSCI quarterly reviews. These were supplemented by the historical list of additions and deletions for each index, which allowed us to generate the point-in-time list of constituents of each index.

\subsection{Market data acquisition and processing}

Table 1 includes the indices' RIC (Reuters Identification Codes) and the total number of constituents as of 11th May 2015 (i.e. 'current constituents') and the number of previous constituents across the entire study period (i.e. 'historical constituents'). There are 45,912 observations for the stock index expiration day analysis, and 10,298 observations for the MSCI rebalance analysis. We retrieved the historical index additions and deletions in order to generate point-in-time snapshots of each index's list of constituents for each unique expiration day. This process starts with the current

Table 1 Market data European indices for the futures and options expiration day analysis and MSCI rebalance analysis

\begin{tabular}{|c|c|c|c|c|c|}
\hline Analysis type & Index RIC & Index name & $\begin{array}{l}\text { Current } \\
\text { constituents }\end{array}$ & $\begin{array}{l}\text { Historical } \\
\text { constituents }\end{array}$ & Location \\
\hline \multirow[t]{7}{*}{$\begin{array}{l}\text { Expiration } \\
\text { day }\end{array}$} & .AEX & $\begin{array}{l}\text { Amsterdam Exchange } \\
\text { Index }\end{array}$ & 25 & 37 & Netherlands \\
\hline & .FCHI & CAC 40 Index & 40 & 58 & France \\
\hline & .FTMIB & FTSE MIB Index & 40 & 51 & Italy \\
\hline & .FTSE & FTSE 100 Index & 100 & 152 & UK \\
\hline & .GDAXI & $\begin{array}{l}\text { Deutsche Boerse } \\
\text { DAX Index }\end{array}$ & 30 & 38 & Germany \\
\hline & .IBEX & IBEX 35 Index & 35 & 44 & Spain \\
\hline &. $\mathrm{OMXS30}$ & $\begin{array}{l}\text { OMX Stockholm } 30 \\
\text { Index }\end{array}$ & 30 & 34 & Sweden \\
\hline $\begin{array}{l}\text { MSCI } \\
\text { rebalance }\end{array}$ & .MSPE & $\begin{array}{l}\text { MSCI International } \\
\text { Pan Euro Price } \\
\text { Index EUR Real } \\
\text { Time }\end{array}$ & 204 & 344 & Europe \\
\hline
\end{tabular}


Table 2 MSCI constituents-country breakdown

\begin{tabular}{llcccc}
\hline Country code & Country name & $\begin{array}{l}\text { Historical } \\
\text { constituent } \\
\text { count }\end{array}$ & $\begin{array}{l}\text { Historical } \\
\text { constituent } \\
\text { percentage }\end{array}$ & $\begin{array}{l}\text { Current } \\
\text { constituent } \\
\text { count }\end{array}$ & $\begin{array}{l}\text { Current } \\
\text { constituent } \\
\text { percentage }\end{array}$ \\
\hline AT & Austria & 6 & 1.74 & 2 & 0.98 \\
BE & Belgium & 10 & 2.91 & 4 & 1.96 \\
CH & Switzerland & 26 & 7.56 & 18 & 8.82 \\
DE & Germany & 39 & 11.34 & 33 & 16.18 \\
DK & Denmark & 8 & 2.33 & 6 & 2.94 \\
ES & Spain & 17 & 4.94 & 12 & 5.88 \\
FI & Finland & 8 & 2.33 & 4 & 1.96 \\
FR & France & 55 & 15.99 & 35 & 17.16 \\
GB & UK & 90 & 26.16 & 43 & 21.08 \\
GR & Greece & 6 & 1.74 & 0 & 0.00 \\
IE & (Republic of) & 5 & 1.45 & 1 & 0.49 \\
IT & Ireland & & & & 6.37 \\
NL & Italy & 23 & 6.69 & 13 & 6.37 \\
NO & Netherlands & 17 & 4.94 & 13 & 1.96 \\
PT & Norway & 8 & 2.33 & 4 & 0.98 \\
SE & Portugal & 3 & 0.87 & 2 & 6.86 \\
\hline & Sweden & 23 & 6.69 & 14 & \\
\hline & & & & & \\
\end{tabular}

constituent list (i.e. as of 11th May 2015), and then iterates the historical log of index additions and deletions by going backwards in time.

Based on the union of current and past constituents, daily market data containing OHLC (open, high, low, close) prices and end-of-day volume is retrieved for each stock. The daily data was extracted with an automated script from Thomson Reuters. We substituted the trading volume of a stock's primary RIC for its consolidated volume, which was computed as the sum of a stock's main exchange trading volume and its volume on MTFs (multilateral trading facilities). The consolidated volume is used throughout this study since it provides a better picture of a stock's real liquidity and this resulting consolidated volume is referenced simply as 'volume' hereafter.

Data pre-processing and cleansing involved filtering stocks with at least 100 days of available daily market data, and appending metadata to each stock, including information such as exchange location and currency.

Table 2 shows the country distribution for the MSCI Pan-European Index, where the two-letter country codes are represented using standard ISO 3166-1 alpha-2. Each stock is associated with a country based on its exchange country; for example, a Spanish stock's country code is GB if this stock is trading on the London Stock Exchange.

\subsection{Calendar data taxonomy}

We manually constructed the stock index futures and options expiration day calendar for 7 European indices and the rebalance calendar for the MSCI quarterly reviews, 
which provide a representative illustration of the main expiration days in Europe for the most liquid indices. A total number of 1042 futures expiration days (with 32,512 observations of daily trading data), 1288 options expiration days (with 46,103 observations of daily trading data), and 49 MSCI rebalance days (with 10,301 observations of daily trading data) are included in the calendar data.

The futures expiration days fall on the third Friday of the expiration month, which occurs either monthly or quarterly (i.e. it follows the quarterly cycle of December, March, June and September). The options expiration days also fall on the third Friday, but they always occur on a monthly basis. When the third Friday is a non-trading day, the stock index futures expiration day is substituted by the previous working day. We did not include the Euro STOXX 50 index since its constituent list overlaps with the blue-chip companies included in the 7 indices listed below. We retrieved each country's non-trading calendar in order to determine if the expiration day for a given index falls on the third Friday of the expiration month or on the previous trading day if the expiration day falls on a bank holiday. The futures contract specifications were retrieved from Euronext (AEX and CAC 40), Eurex Exchange (DAX 30), London Stock Exchange (FTSE 100), Borsa Italiana (FTSE MIB), Bolsas y Mercados Españoles (IBEX 35) and NASDAQ OMX (OMXS30); the options contract expiration days were collected from Bloomberg. The stock index futures and options expiration day calendar covers the following 7 indices, where only FTSE 100 and DAX have quarterly futures expiration days:

- FTSE 100 Index Futures and Options;

- CAC 40 Index Futures and Options;

- DAX 30 Index Futures and Options;

- FTSE MIB Index Futures and Options;

- IBEX 35 Index Futures and Options;

- Amsterdam Exchange (AEX) Index Futures and Options;

- OMX Stockholm 30 (OMXS30) Index Futures and Options.

With the exception of the two quarterly futures expiration indices (i.e. FTSE 100 and DAX 30), where the futures expiration day overlaps with the options expiration day only once every 3 months per quarter, the options and futures expiration days fall exactly on the same date.

The MSCI rebalances are typically implemented on the last trading day of the following quarterly cycle: February, May, August, and November. However, there are very few exceptions when the MSCI quarterly review date falls a few days before the end of the month. When the rebalance day falls on a trading holiday in a given market, then the relevant trading date of MSCI rebalance is the closest previous trading day. The machine-generated review dates were checked against the quarterly index review documents from www.msci.com and span from February 2003 until May 2015.

\subsection{Trading volume summary statistics}

Figures 1 and 2 illustrate the surges in trading volume on index options and futures expiration days and MSCI quarterly reviews, respectively. In these figures, the trading volume is normalised as the mean daily volume percentage of the cumulative monthly vol- 


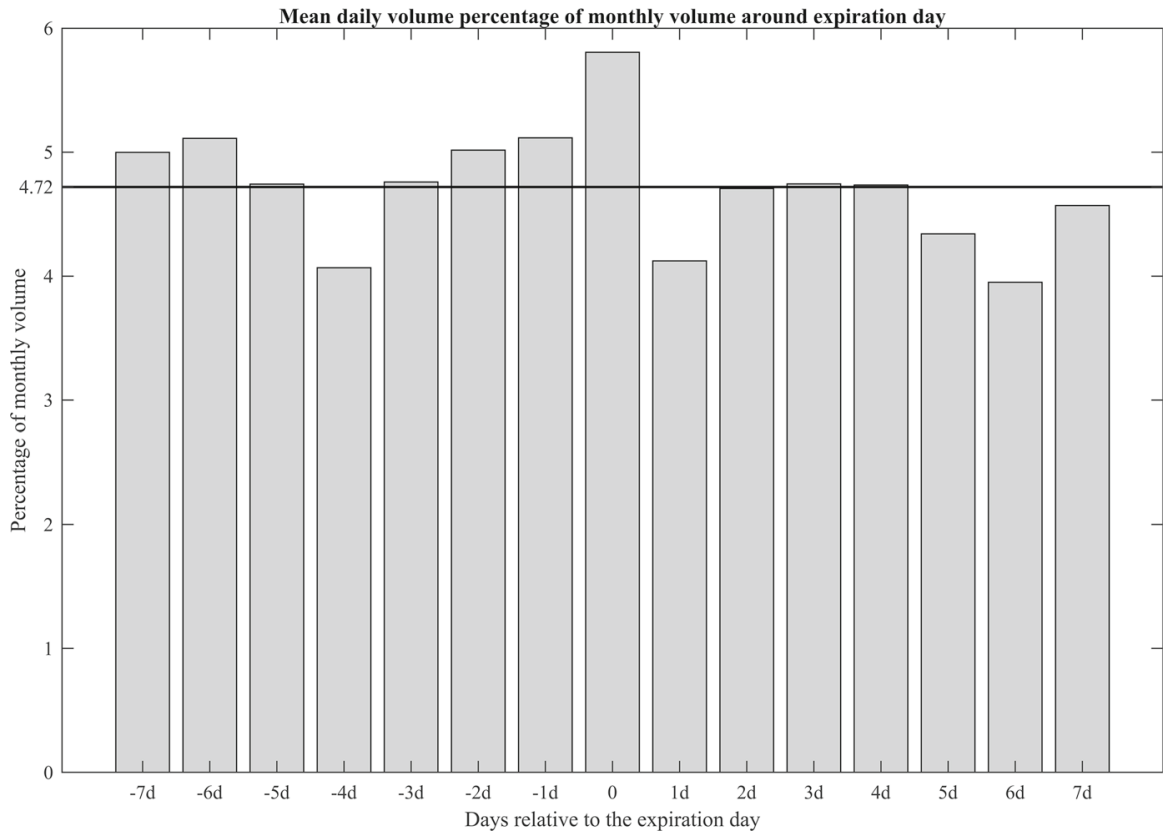

Fig. 1 Mean daily volume percentage of monthly volume around expiration days

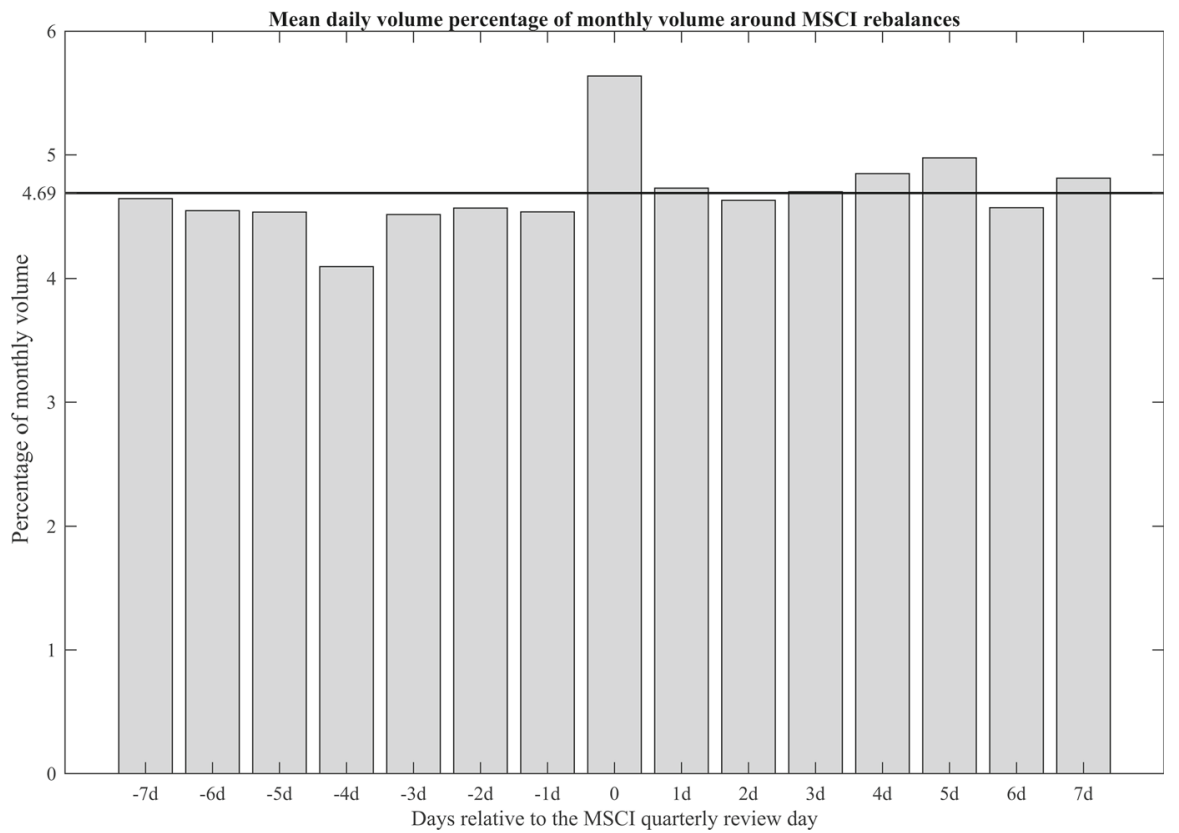

Fig. 2 Mean daily volume percentage of monthly volume around MSCI rebalances 
ume. The normalised volumes on index options and futures expiration days and MSCI rebalances are significantly higher than the trading volumes during the 7 trading days in the run-up to the expiration day or MSCI rebalance or during the 7 trading days following these events. Both of these histograms include a horizontal line representing the average across all bins. Figure 1 is based on 66,471 observations of monthly volume for the 403 relevant stocks having minimum 15 daily market data observations per month.

Figure 2 shows the mean daily volume percentage of monthly volume around MSCI rebalances of 59,083 observations of monthly trading volume for the 338 relevant stocks having at least 15 observations of daily market data per month.

\section{Analysis approach}

This section describes the analytical approach for the index expiration day and MSCI rebalance models. The study commences by validating the existence of the investigated phenomena (i.e. the index options and futures expiration day and the MSCI rebalance, and their relation with an increase in trading activity) by exploring a linear regression model and then employing randomisation tests. Once the existence of these effects is confirmed in the European equity markets as being statistically significant, we build a predictive model, by fitting a number of stepwise regression model (i.e. linear regression models, followed by sequential feature selection) for the index options and futures expiration day, and MSCI rebalance.

The volume on a special date (also called 'target date' or $t_{0}$, i.e. futures and options expiration days, or MSCI rebalances) is compared with the volume of a benchmark period, which was defined as the median of the 20 trading days prior to a given future expiration day or MSCI rebalance. We chose the median as a measure of central tendency because median is robust to outliers. The study involves data that are periodic, but sparse. There is a number of expiration days and rebalances and we normalise the analysis data in order to identify effects that are common to some stocks and a particular target date, either index options and futures expiration day or MSCI rebalance.

The study also considers a multi-step ahead prediction, up to a step size of 6 trading days. For instance, a 6-step ahead analysis would compute the benchmark volume for the previous 20 trading days for a given date in order to predict the volume impact in 6 days' time. The default analyses in this study consider one-step ahead forecasting, although the default step size of $n=1$ day can be lagged and therefore the step ahead lag is defined as lag $=n-1$. Based on this notation, we define the relative volume for a given expiration or rebalance as the log-ratio between the volume on expiration/rebalance day and its benchmark volume, computed as the median of the previous 20 trading days, as shown in Eq. (1). The target variable in all regression models in this study is the relative volume.

$$
V_{\text {rel }}=\log \frac{V_{t 0}}{\operatorname{median}\left(V_{t-\text { lag-1 }}, V_{t-\text { lag-2 }}, \ldots, V_{t-\text { lag-20 }}\right)}
$$

The index expiration day and MSCI rebalance analyses investigated an anterior or posterior effect in the trading volumes, and therefore, it allowed for offsets relative 
to the target date, ranging from -5 days to +5 days. For example, for an offset of -3 days, we compute the target date by subtracting 3 trading days from the main target date (i.e. the expiration or rebalance day). A zero-offset analysis considers the expiration day or rebalance day itself. Consequently, we could analyse when the trading volume starts increasing and when it returns to the normal level.

The analysis models are classified into expiration day models and rebalance models, and are fit on different data sets (i.e. different indices). Since we allow for target date offsets, both model classes are fit with and without indicator variables for the number of days relative to the expiration/rebalance day, resulting in 11 additional predictors (ranging from -5 days to +5 days).

\section{Descriptive modelling}

Before validating this paper's hypotheses by conducting a series of randomisation tests and exploring the predictive models in Sect. 7, we provide an OLS descriptive model to explore the positive relationship between the predictors and the target variable, i.e. the trading volume. To this end, we fit two OLS models, one for the index futures and options expiration day and one for the MSCI rebalance, respectively, based on the observed market data of the stocks that were a point-in-time constituent of the analysed indices.

The first OLS model, outlined in Eq. (2), fits the trading volume as a linear function of the indicator variable $D_{t}^{\text {Exp }}$ indicating whether that day is an expiration day (either options or futures expiration day), and two control variables for the day-of-the-week effect, consisting of an indicator variable $D_{t}^{\text {Thu }}$ flagging whether that observation falls on a Thursday and $D_{t}^{\text {Fri }}$ flagging whether it is a Friday. These two day-of-the-week dummy variables were chosen based on the distribution of expiration days, as outlined in Table 4. The high coefficient of the expiration day predictor in Table 3 suggests a positive effect on trading volume when the observation is an index options and futures expiration day. The regression design matrix is constructed on 967,278 observations, out of which 45,743 observations fall on expiration days.

$$
V_{t}=\alpha+\beta_{\mathrm{Exp}} D_{t}^{\mathrm{Exp}}+\beta_{\mathrm{Thu}} D_{t}^{\mathrm{Thu}}+\beta_{\mathrm{Fri}} D_{t}^{\mathrm{Fri}}+\epsilon_{t}
$$

The OLS in Eq. (3) regresses the trading volume on two predictors: the indicator variable $D_{t}^{\text {Reb }}$ flagging whether the observation is an MSCI rebalance day and the indicator variable $D_{t}^{\mathrm{EoM}}$, which is ' 1 ' if the observation falls at least on the 25 th day

Table 3 Index expiration day OLS coefficients

\begin{tabular}{lcrl}
\hline Predictor & Coefficient estimate & $t$ statistic & $p$ value \\
\hline Constant term & -0.02115 & -33.872 & $2.43 \mathrm{E}-251$ \\
Expiration day & 0.20759 & 82.171 & 0 \\
Thursday & 0.09108 & 73.269 & 0 \\
Friday & 0.01918 & 13.877 & $8.82 \mathrm{E}-44$ \\
\hline
\end{tabular}


Table 4 Index options and futures expiration day: day-of-the-week distribution

Table 5 Day-of-the-month distribution of MSCI rebalances

Table 6 MSCI rebalance OLS coefficients

\begin{tabular}{lrc}
\hline Value & Count & Percentage \\
\hline 1 & 0 & 0.00 \\
2 & 0 & 0.00 \\
3 & 29 & 0.06 \\
4 & 1179 & 2.58 \\
5 & 44,535 & 97.36 \\
\hline
\end{tabular}

\begin{tabular}{lrc}
\hline Value & Count & Percentage \\
\hline $1-24$ & 0 & 0.00 \\
25 & 415 & 4.04 \\
26 & 573 & 5.58 \\
27 & 610 & 5.94 \\
28 & 1911 & 18.60 \\
29 & 1212 & 11.80 \\
30 & 2535 & 24.67 \\
31 & 3018 & 29.38 \\
\hline
\end{tabular}

\begin{tabular}{lccl}
\hline Predictor & Coefficient estimate & $t$ statistic & $p$ value \\
\hline Constant term & 0.02497 & 38.9340841 & 0 \\
Rebalance day & 0.24803 & 52.2687882 & 0 \\
End of month & -0.09117 & -62.476414 & 0 \\
\hline
\end{tabular}

of the month and ' 0 ' otherwise. This end-of-month dummy variable splits the month on the 25th day of the month based on the distribution outlined in Table 5, where all MSCI quarterly review dates are falling on or after the 25 th day of the month. The OLS design matrix has 654,229 observations, with 10,274 being MSCI rebalance days. Table 6 includes the coefficients of the regression model; the high rebalance day coefficient suggests a positive impact on the trading volume when the observation falls on an MSCI quarterly review day.

$$
V_{t}=\alpha+\beta_{\mathrm{Re} b} D_{t}^{\mathrm{Re} b}+\beta_{\mathrm{EoM}} D_{t}^{\mathrm{EoM}}+\epsilon_{t}
$$

\section{Randomisation analysis}

The following randomisation tests address the existence of higher trading activity on the expiration and rebalance days. We test the futures and options expiration day effect against the Friday effect, and the MSCI rebalance effect against the end-ofmonth effect with regard to higher trading activity. Their control dates account for the 
day-of-the-week effect and maintain the same proportion of days of the week as the target dates.

The existence of potential structural breaks is analysed in the following randomisation tests in order to allow us to assume structural homogeneity. For this reason, the sample period is divided in two halves (i.e. 1st January 2000-31st December 2007 and 1st January 2008-10th May 2015), and each of these subsamples is analysed, along with the entire sample period. The rationale of dividing the sample on 1st January 2008 is twofold: first, this is an approximate midpoint for our entire sample period; and, second, this coincides with the financial crisis of 2007-2008, whose peak was reached when Lehman Brothers collapsed on 15th September 2008.

The randomisation test generally checks whether two data vectors are significantly different. The difference between these vectors' means is the observed statistic. We randomise the two vectors' labels 1000 times and we compute the newly reshuffled vectors' mean difference. Eventually we test whether the randomised differences are more extreme than the observed difference, resulting in an empirical $p$ value, which is calculated as the percentage of randomisations where the observed difference is larger (for the right-tailed or two-tailed tests) or smaller (for the left-tailed test) than the randomised differences. The $p$ value represents the probability of observing a test statistic at least as extreme as the observed value under the null hypothesis, and if it is small then the validity of the null hypothesis is considered uncertain. When the empirical $p$ value is below the chosen significance level $(\alpha=5 \%)$, we reject the null hypothesis.

All of the following randomisation tests are pairwise, and, for each target date, a particular control date is chosen, which is conditioned on the target date. Therefore, the labels are reshuffled on a pairwise basis, flipping a coin for each element in order to decide whether to interchange the target date and the control date.

\subsection{Index options and futures expiration days versus control dates}

The target dates for the randomisation test between index expiration days and control dates consist of all futures and options expiration dates. There are 32,408 observations of trading days when there are both an index options expiration day and an index futures expiration day. For each target date, we choose the closest control date that falls exactly one or 2 weeks before or after the expiration day. Therefore, the control date falls on the same day of the week as the target date. The test is conducted for each target date offset. When the offset is positive, we do not allow the control date to fall 1 week before the target date, as it would overlap with the critical days around the expiration day. Similarly, when the offset is negative, the control date cannot fall 1 week after the target date. There is a two-tailed test and a right-tailed test. The null hypothesis of the two-tailed test is that the difference between the relative trading volume on the (offset) index options and futures expiration days and the relative trading volume of the control dates comes from a distribution with zero mean, whereas the alternative hypothesis of the right-tailed test is that the mean of the index options and futures expiration day relative volumes is less than the mean of the control date relative volumes. 
Table 7 Randomisation tests between index options and futures expiration days and control dates-no target date offset, 1-step ahead modelling

\begin{tabular}{|c|c|c|c|c|c|c|}
\hline $\begin{array}{l}\text { Analysis } \\
\text { type }\end{array}$ & Index RIC & $\begin{array}{l}\text { Unique stocks } \\
\text { (historical } \\
\text { constituents) }\end{array}$ & Target dates & $\begin{array}{l}\text { Randomisation } \\
\text { tail (s) }\end{array}$ & $p$ value & Reject $H_{0}$ \\
\hline \multirow{14}{*}{$\begin{array}{l}\text { Individual } \\
\text { index }\end{array}$} & .FTSE & 149 & 5023 & Both & 0 & Yes \\
\hline & .FTSE & 149 & 5023 & Right & 0 & Yes \\
\hline & .GDAXI & 37 & 1724 & Both & 0 & Yes \\
\hline & .GDAXI & 37 & 1724 & Right & 0 & Yes \\
\hline & .FCHI & 54 & 6929 & Both & 0 & Yes \\
\hline & .FCHI & 54 & 6929 & Right & 0 & Yes \\
\hline & .FTMIB & 51 & 4934 & Both & 0 & Yes \\
\hline & .FTMIB & 51 & 4934 & Right & 0 & Yes \\
\hline & .IBEX & 44 & 5307 & Both & 0 & Yes \\
\hline & .IBEX & 44 & 5307 & Right & 0 & Yes \\
\hline & .AEX & 37 & 3633 & Both & 0 & Yes \\
\hline & .AEX & 37 & 3633 & Right & 0 & Yes \\
\hline &. $\mathrm{OMXS} 30$ & 33 & 4858 & Both & 0 & Yes \\
\hline &. $\mathrm{OMXS30}$ & 33 & 4858 & Right & 0 & Yes \\
\hline \multirow[t]{2}{*}{ All indices } & $\begin{array}{l}\text {.FTSE, .GDAXI, } \\
\text {.FCHI, .FTMIB, } \\
\text {.IBEX, .AEX, } \\
\text {.OMXS30 }\end{array}$ & 401 & 32,408 & Both & 0 & Yes \\
\hline & $\begin{array}{l}\text {.FTSE, .GDAXI, } \\
\text {.FCHI, .FTMIB, } \\
\text {.IBEX, .AEX, } \\
\text {.OMXS30 }\end{array}$ & 401 & 32,408 & Right & 0 & Yes \\
\hline
\end{tabular}

Table 7 shows the randomisation test results for the index options and futures expiration day (i.e. no offset), using 1-step ahead modelling. The results include the aggregated indices, along with a breakdown by individual index, and monthly versus quarterly expiration day indices. Table 8 shows the results for the aggregated indices for offsets -5 days to +5 days. The randomisation tests reveal that the trading volume on the expiration day of each index is significantly higher. This is also the case for offsets ' -1 ', ' +1 ' and ' +2 ', meaning that the trading volume surges 1 day before the expiration day and remains at high levels for two trading days after the expiration day. The results are consistent across the sample period halves and there are no structural breaks for the futures and options expiration elevated volume. The multi-step ahead modelling rejects the null hypothesis for the same offsets, although the $p$ value varies insignificantly in very few instances, without changing the null hypothesis rejection decision. Figure 3 illustrates the relative volume cumulative distribution for dates with index expiration days (i.e. target dates) and dates with no index expiration days (i.e. control dates), exhibiting larger trading volumes on futures and options expiration days. 
Table 8 Randomisation tests between index options and futures expiration days and control dates-all indices, 1-step ahead modelling

\begin{tabular}{llllll}
\hline Target date offset & $\begin{array}{l}\text { Unique stocks } \\
\text { (historical } \\
\text { constituents) }\end{array}$ & Target dates & $\begin{array}{l}\text { Randomisation tail } \\
(\mathrm{s})\end{array}$ & $p$ value & Reject $H_{0}$ \\
\hline 0 & 401 & 32,408 & Both & 0 & Yes \\
0 & 401 & 32,408 & Right & 0 & Yes \\
-5 & 401 & 32,413 & Both & 0 & Yes \\
-5 & 401 & 32,413 & Right & 1 & No \\
-4 & 401 & 32,406 & Both & 0.008 & Yes \\
-4 & 401 & 32,406 & Right & 0.003 & Yes \\
-3 & 401 & 32,403 & Both & 0.011 & Yes \\
-3 & 401 & 32,403 & Right & 0.002 & Yes \\
-2 & 401 & 32,411 & Both & 0.144 & No \\
-2 & 401 & 32,411 & Right & 0.041 & Yes \\
-1 & 401 & 32,414 & Both & 0 & Yes \\
-1 & 401 & 32,414 & Right & 0 & Yes \\
1 & 401 & 32,415 & Both & 0 & Yes \\
1 & 401 & 32,415 & Right & 0 & Yes \\
2 & 401 & 32,416 & Both & 0 & Yes \\
2 & 401 & 32,416 & Right & 0 & Yes \\
3 & 401 & 32,411 & Both & 0 & Yes \\
3 & 401 & 32,411 & Right & 1 & No \\
4 & 401 & 32,411 & Both & 0 & Yes \\
4 & 401 & 32,411 & Right & 1 & No \\
5 & 401 & 32,407 & Both & 0 & Yes \\
5 & 401 & 32,407 & Right & 1 & No \\
\hline
\end{tabular}

\subsection{Index options and futures expiration days versus Fridays}

Next, we investigate whether the higher volume associated with the futures and options expiration days is actually caused by the Friday effect or whether it is driven solely by the index options and futures expiration day. The target dates consist of all futures and options expiration days falling on Fridays. There are 30 instances of expiration days falling on the previous day, i.e. on a Thursday. These 30 non-Friday expiration days belong to various indices and there are actually 13 unique non-Friday expiration days, associated with 912 stocks that have been discarded for this randomisation test. The control date for each target date is the closest Friday (in terms of the difference in calendar days from the target date) falling 1 or 2 weeks from the expiration day (i.e. $-2,-1,+1,+2$ week/s relative to the expiration day). The alternative hypothesis is that the relative volume on index options and futures expiration days is significantly different from (for the two-tailed test) or larger than (for the right-tailed test) the relative volume on non-expiration Fridays. The randomisation tests in Table 9 reject the null 


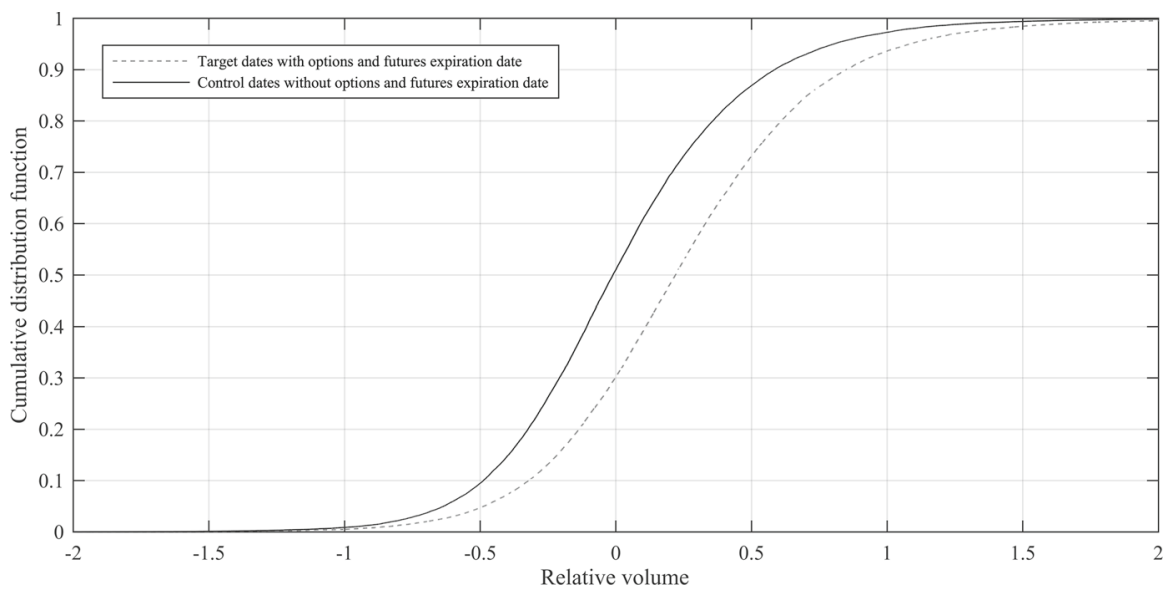

Fig. 3 Relative volume cumulative distribution for dates with index options and futures expiration days and dates with no expiration days

Table 9 Randomisation tests between index options and futures expiration days and Fridays-1-step ahead modelling, all futures and options indices

\begin{tabular}{lllll}
\hline $\begin{array}{l}\text { Unique stocks (historical } \\
\text { constituents) }\end{array}$ & Target dates & Randomisation tail (s) & $p$ value & Reject $H_{0}$ \\
\hline 401 & 31,496 & Both & 0 & Yes \\
401 & 31,496 & Right & 0 & Yes \\
\hline
\end{tabular}

hypothesis and conclude that the Fridays with futures and options expiration days are the drivers of increased volumes on Fridays. The results are consistent among the two sample halves, i.e. 2000-2007 and 2008-2015. Figure 4 contains the cumulative distributions of the relative volume for the Fridays with and without index options and futures expiration days and illustrates the larger volumes associated with the expiration Fridays.

\subsection{MSCl rebalances versus control dates}

We further test whether the relative trading volume on MSCI rebalances is higher than the volume on the last trading day of the previous or following month. The target dates consist of all (offset) MSCI rebalance days. For each target date, we find the closest control date that is the last trading day of the previous or the following month. If the target date is offset, then the control date is offset as well. We perform a two-tailed test and a right-tailed test. The alternative hypothesis of the two-tailed test is that the relative trading volume of the relative dates is significantly different from the volume on control dates, whereas the alternative hypothesis of the right-tailed test is that the relative volume of the target dates is larger than the relative volume of the control dates. Table 10 shows the randomisation test results, which confirm that the relative 


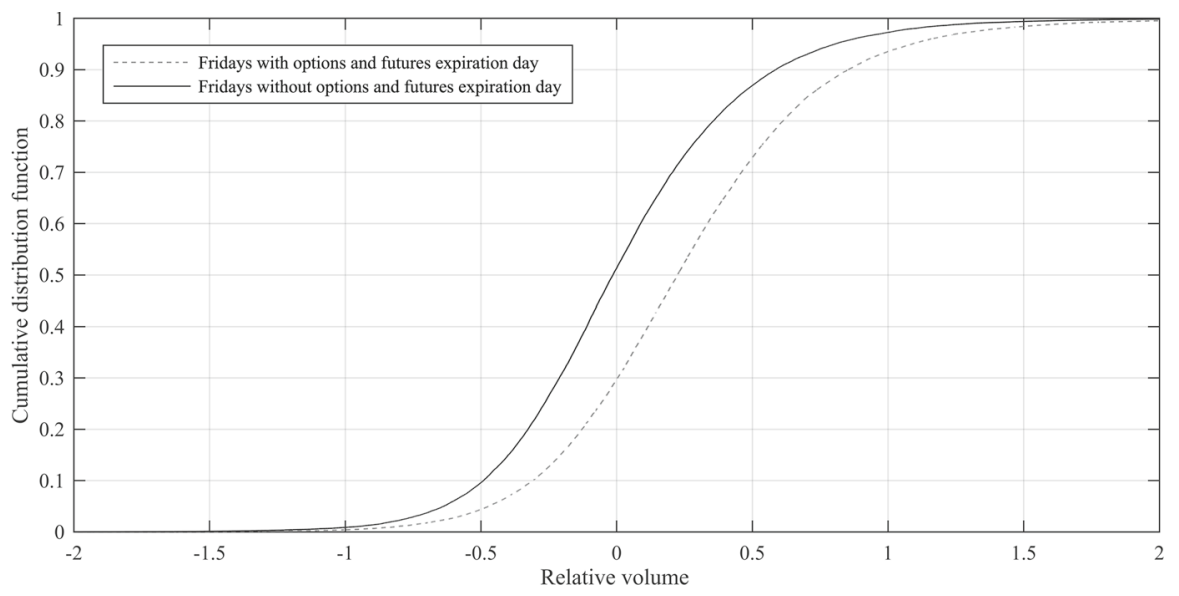

Fig. 4 Relative volume cumulative distribution for Fridays with index options and futures expiration days and Fridays with no index expiration days

Table 10 Randomisation tests between MSCI rebalances and control dates-1-step ahead modelling

\begin{tabular}{llllll}
\hline $\begin{array}{l}\text { Target date } \\
\text { offset }\end{array}$ & $\begin{array}{l}\text { Unique stocks } \\
\text { (historical constituents) }\end{array}$ & Target dates & Randomisation tail (s) & $p$ value & Reject $H_{0}$ \\
\hline 0 & 338 & 10,298 & Both & 0 & Yes \\
0 & 338 & 10,298 & Right & 0 & Yes \\
-5 & 338 & 10,340 & Both & 0 & Yes \\
-5 & 338 & 10,340 & Right & 1 & No \\
-4 & 338 & 10,338 & Both & 0 & Yes \\
-4 & 338 & 10,338 & Right & 1 & No \\
-3 & 338 & 10,341 & Both & 0.181 & No \\
-3 & 338 & 10,341 & Right & 0.069 & No \\
-2 & 338 & 10,341 & Both & 0 & Yes \\
-2 & 338 & 10,341 & Right & 1 & No \\
-1 & 338 & 10,341 & Both & 0.002 & Yes \\
-1 & 338 & 10,341 & Right & 0 & Yes \\
1 & 338 & 10,341 & Both & 0.726 & No \\
1 & 338 & 10,341 & Right & 0.377 & No \\
2 & 338 & 10,337 & Both & 0 & Yes \\
2 & 338 & 10,337 & Right & 1 & No \\
3 & 338 & 10,337 & Both & 0 & Yes \\
3 & 338 & 10,337 & Right & 1 & No \\
4 & 338 & 10,338 & Both & 0 & Yes \\
4 & 338 & 10,338 & Right & 1 & No \\
5 & 338 & 10,340 & Both & 0.001 & Yes \\
5 & 338 & 10,340 & Right & 1 & No \\
\hline
\end{tabular}




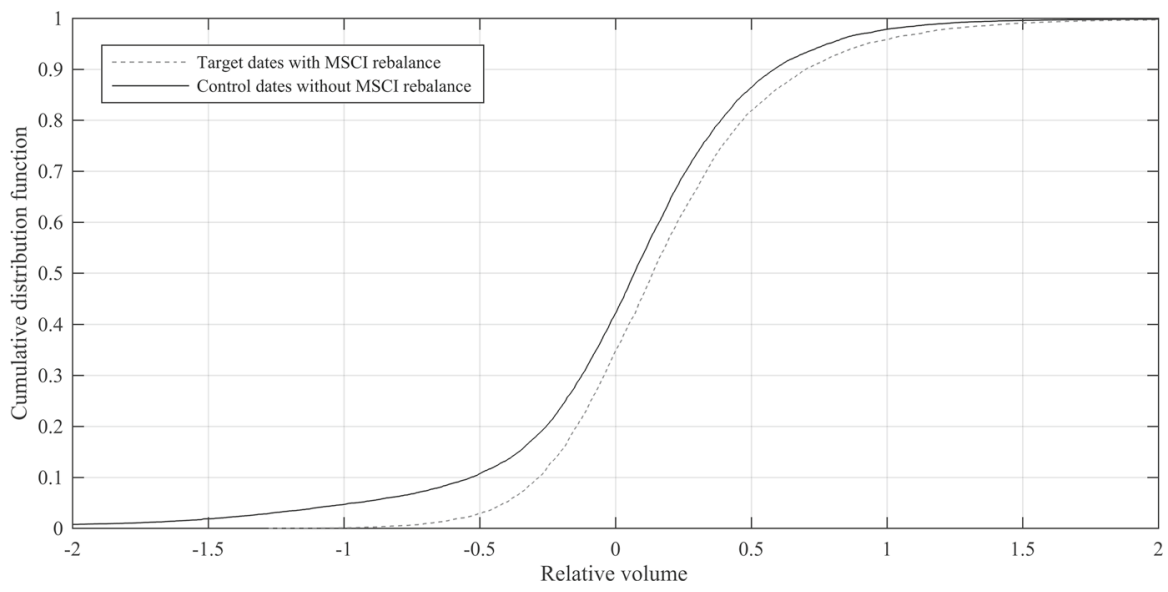

Fig. 5 Relative volume cumulative distribution for dates with MSCI rebalances and dates with no MSCI rebalances

volume on MSCI rebalances is significantly higher than the relative volume of the last trading days of the months without MSCI rebalances. This is also the case for offset '- 1' (for 1-step ahead and 2-step ahead analyses only). Therefore, the trading volume surges one day before the review date, and then goes back to the normal level after the rebalancing. The same results are obtained for 2000-2007. Slightly different results are generated for 2008-2015, where the offset with larger volume is ' +1 ', instead of '- 1' trading days. We conclude that the trading volumes are generally larger on the trading day before the review day and on the effective MSCI rebalance day.

Figure 5 illustrates the relative volume cumulative distribution for dates with MSCI rebalances (i.e. target dates) being slightly higher than the relative volumes on dates with no MSCI rebalances (i.e. control dates).

\subsection{MSCl rebalances versus end-of-month effects}

The randomisation test between MSCI rebalances and end-of-month effects aims to identify the main driver of larger volumes around the end of the month. For this test, we define the relative monthly trading volume as outlined in Eq. (4). We use the arithmetic mean instead of median (as with the relative volumes for a certain target date) because in this case, we are quantifying the volumes occurring at the beginning of month and at the end of the month, and the arithmetic mean better incorporates all observations throughout these periods. Certain volume trends occur over multiple dates, and therefore, such effects would be better accounted for by using the arithmetic mean.

$$
V_{\text {rel month }}=\log \frac{\text { mean }(\text { last } 5 \text { trading days of the month })}{\text { mean(first } 10 \text { trading days of the month })}
$$

The target dates consist of all MSCI rebalance months. For each MSCI quarterly review month, we consider the previous and following months and ultimately flip a 
Table 11 Randomisation tests between MSCI rebalances and end-of-month effects-1-step ahead modelling

\begin{tabular}{llllll}
\hline Sample period (s) & Stocks & Target dates & Randomisation tail (s) & $p$ value & Reject $H_{0}$ \\
\hline $\begin{array}{l}\text { 2000-2007, 2008-2015, } \\
\text { 2000-2015 }\end{array}$ & 338 & 10,298 & Both & 0.005 & Yes \\
& 338 & 10,298 & Right & 0.999 & No \\
\hline
\end{tabular}

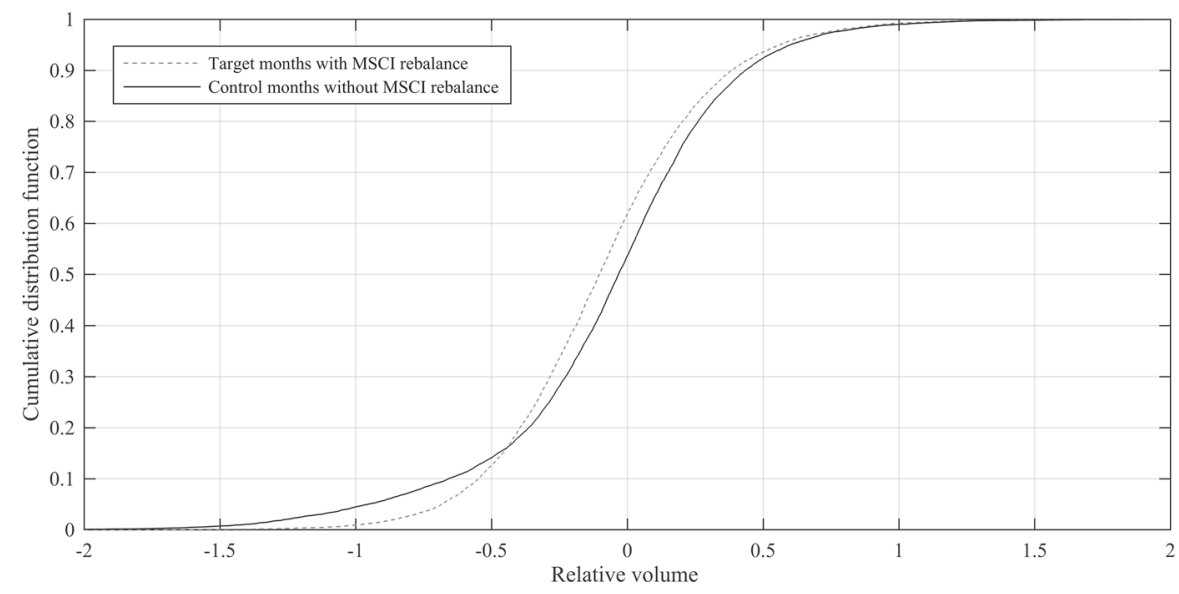

Fig. 6 Relative volume cumulative distribution for months with MSCI rebalance and months with no MSCI rebalances

coin in order to choose whether the previous month or the following month is selected as the control date. We perform a two-tailed test and a right-tailed test for the relative monthly volume of the target months and control months. The alternative hypothesis is that the relative monthly volume on MSCI quarterly review months is significantly different from (for the two-tailed test) or significantly larger than (for the right-tailed test) the relative monthly volume on the months with no MSCI rebalance. Based on the results in Table 11, we report that volume on MSCI rebalance months is significantly different from the volume on months with no MSCI review, but the large trading activity associated with the MSCI rebalances cannot explain the large volumes around the end of the month. Figure 6 visually supports this conclusion and illustrates the relative volume cumulative distribution for months with MSCI rebalances (i.e. target months) and months with no MSCI rebalances (i.e. control months). The monthly volume on MSCI review months has a higher kurtosis than the months with no MSCI rebalances; the monthly volume for control dates has more extreme values on both tails, having a larger dispersion than the target months.

\subsection{Summary}

The previous randomisation tests provide a methodological rigour for inferring a conclusion with regard to the existence of the studied phenomena. The tests generally 
found no structural breaks around the financial crisis of 2007-2008, with the exception of a reversing effect for a couple of days adjacent to the MSCI quarterly review dates.

We report significantly higher trading volumes associated with both index options and futures expiration days (starting one day before the expiration day and lasting two days after the expiration day) and MSCI rebalances (starting on the day preceding the rebalance and returning to normal levels the following day after the quarterly review day) relative to the pairwise control dates. However, when comparing the volume on special dates, i.e. index options and futures expiration days and MSCI rebalances, to the cumulative volume on the adjacent days, we can only observe higher trading volume on the expiration day and quarterly review date themselves. We found that the Friday effect does not explain the surge in volumes on futures and options expiration days. Despite presenting evidence that the trading volumes of the months with MSCI quarterly reviews are statistically significant, we draw the conclusion that the larger volumes of the MSCI rebalances cannot explain the end-of-month effect.

\section{Predictive modelling}

Given the empirical evidence provided by the randomisation tests and the OLS regression, we further investigate the effect size of the index options and futures expiration days and MSCI rebalances in connection with trading volume.

\subsection{Modelling approach}

The models follow a general stepwise regression framework, which starts by collecting the data, depending on the model (i.e. expiration day or rebalance model), and aggregates the predictors for each target date in the regression matrix. It then performs stratified partitioning on the data set, by creating tenfolds of random subsamples with similar proportions of observation classes. Each class is defined for a unique combination of values for the indicator variables (i.e. predictors whose values are only binary, e.g. 'trading country code', 'expiration day index RIC', 'offset $\pm n$ days' etc.). The stratified partitioning provides robust results since the classes are evenly distributed across the folds, especially when the data set is unbalanced, and the models are trained and tested based on observations from all classes. Once the tenfolds are defined, the framework proceeds to fitting a multiple linear regression, followed by forward feature selection, where the variable selection objective function minimises the mean squared error (MSE) using tenfold cross-validation (CV). We did not use backward elimination because the models are defined with a constant term (or intercept) and the regression design matrix contains full categorical variables (i.e. categorical variables with $n$ possible values are encoded as $n$ predictors, instead of $n-1$, because we are exploring the statistical significance of these predictors and perform feature selection on the $n$ possible values) and would lead to multicollinearity issues, where the regression design matrix is rank deficient. 
The study also investigates the volume autoregression in the context of special dates (i.e. expiration days and rebalances). Hence, we fit the two model classes with and without 20 lagged volumes, which are normalised by dividing them by their benchmark volume (i.e. the median of the 20 lagged volumes). The volume normalisation is performed in order to account for the different magnitude of the trading volume across different stocks. The normalisation is consistent with the relative volume, which also divides the target volume by the benchmark volume.

We fit a linear regression model for the stock index futures and options effect, and another one for the MSCI rebalance effect. All of the models contain a constant/intercept term. We reduce the dimensionality of these full models by performing sequential feature selection and retrieving a reduced model with fewer features (or predictor variables), while minimising the predictive error of the fit models using different subsets. When performing feature selection, the intercept is always kept in the reduced model. Similarly, if a given model is defined with 20 lagged volumes, these predictors are kept in the model. The objective function of the sequential feature selection seeks to minimise the criterion, which we chose to be the MSE, throughout the potential feature subsets.

We employed a forward selection sequential search algorithm for feature selection, where features are sequentially added to the starting model (i.e. only the constant/intercept term, and possibly the 20 lagged volumes) until no other features can be added in order to decrease the criterion. It is unfeasible to have an exhaustive approach and fit all the feature subsets of a model with $n$ features due to time and processing constraints, and therefore, the sequential search algorithm moves only in one direction, always growing the candidate feature set (if using forward selection).

Every time a candidate feature is added to or removed from the model feature set, the candidate model with the new feature set is cross-validated using the objective function, which minimises the MSE criterion. Tenfold stratified cross-validation is applied throughout the analyses of this study, using the same tenfolds that were initially defined in the stratified partitioning of the data set.

\subsection{Model outline}

There are eight full models that are fit in this study, and Table 12 outlines their full candidate feature sets. The features whose names are marked in italics on the left-hand

Table 12 Regression models-full candidate features

\begin{tabular}{|c|c|c|c|c|c|c|c|c|}
\hline \multirow[b]{2}{*}{ Intercept } & \multicolumn{4}{|c|}{$\begin{array}{l}\text { Index expiration } \\
\text { day models }\end{array}$} & \multicolumn{4}{|c|}{$\begin{array}{l}\text { MSCI rebalance } \\
\text { models }\end{array}$} \\
\hline & $r$ & $\checkmark$ & $\checkmark$ & $\checkmark$ & $\checkmark$ & $\checkmark$ & $\checkmark$ & $\checkmark$ \\
\hline Trading country code & & & & & $\checkmark$ & $\checkmark$ & $\checkmark$ & $\boldsymbol{V}$ \\
\hline Expiration day index RIC & $\checkmark$ & $\checkmark$ & $\checkmark$ & $\checkmark$ & & & & \\
\hline Target date offset (from -5 to 5 days) & $\boldsymbol{V}$ & $\checkmark$ & & & $\boldsymbol{V}$ & $\checkmark$ & & \\
\hline 20 lagged normalised volumes & $\boldsymbol{V}$ & & $v$ & & $\checkmark$ & & $\checkmark$ & \\
\hline
\end{tabular}


side column indicate multiple features. For instance, 'Trading country' would substitute country by each trading country of the constituents of the MSCI Pan-European Index, e.g. 'Trading GB', 'Trading DE', 'Trading FR' etc. There are also 20 features for the lagged normalised volume corresponding to each trading day.

The study provides two separate model classes for the expiration day effect, one for the stock index options and futures expiration day and one for the MSCI quarterly index review.

\subsubsection{Index expiration day models}

For this part of the study, we use the stocks that are members of one of the 7 indices allowing for futures and options. The target date can vary from 5 days prior to the expiration day to 5 days after the expiration day, and therefore, the benchmark period of 20 days is shifted accordingly, accounting for the chosen step size as well (expressed in days). The left-hand side column in Fig. 7 (i.e. Panels A-F) shows the relative volume distribution for the negative target date offsets, ranging from 1 to 5 days prior to the index options and futures expiration day, whereas the right-hand side column, corresponding to Panels G-L, includes the positive target date offsets, ranging from 1 to 5 days after the expiration days. In both columns, the top panel (i.e. Panel A and Panel G) illustrates the volume on the index options and futures expiration day. There is a rather negatively skewed distribution of the relative volume on the expiration day and on the 2 days in the run-up to the expiration day.

The stock index futures and options expiration day models include the constant term and 7 'expiration day index RIC' indicator variables. Depending on the model definition, the predictors of some models could include 20 lagged normalised volumes and 11 indicator variables for the target date offset (ranging from -5 days to +5 days), where the 0 target date offset is the actual expiration day; this indicator variable is always part of the design matrix regardless of the target date offset configuration.

\subsection{2 $\mathrm{MSCl}$ rebalance models}

The MSCI rebalance effect analysis consists of 204 constituents of the MSCI International Pan Euro Price Index from 15 European countries. This is a heuristic approach having a general date for MSCI quarterly index review, which does not account accurately for every country. The target date of the regression model can vary from 5 days prior to the rebalance day to 5 days after the rebalance day. The benchmark volumes are calculated depending on the chosen target date and step size. The model full candidate features include the intercept and 'trading country code' for each of the unique countries where MSCI constituents trade in. Certain model definitions allow for 11 indicator variables for the target date offset (from -5 days to +5 days) and 20 lagged normalised volumes.

Figure 8 contains the relative volumes for the negative target date offsets on the left-hand side column, corresponding to Panels A-F, and the positive target date offsets, corresponding to Panels G-L. The figure illustrates the slight negatively skewed distribution of the relative volume on the MSCI quarterly index review day only. 

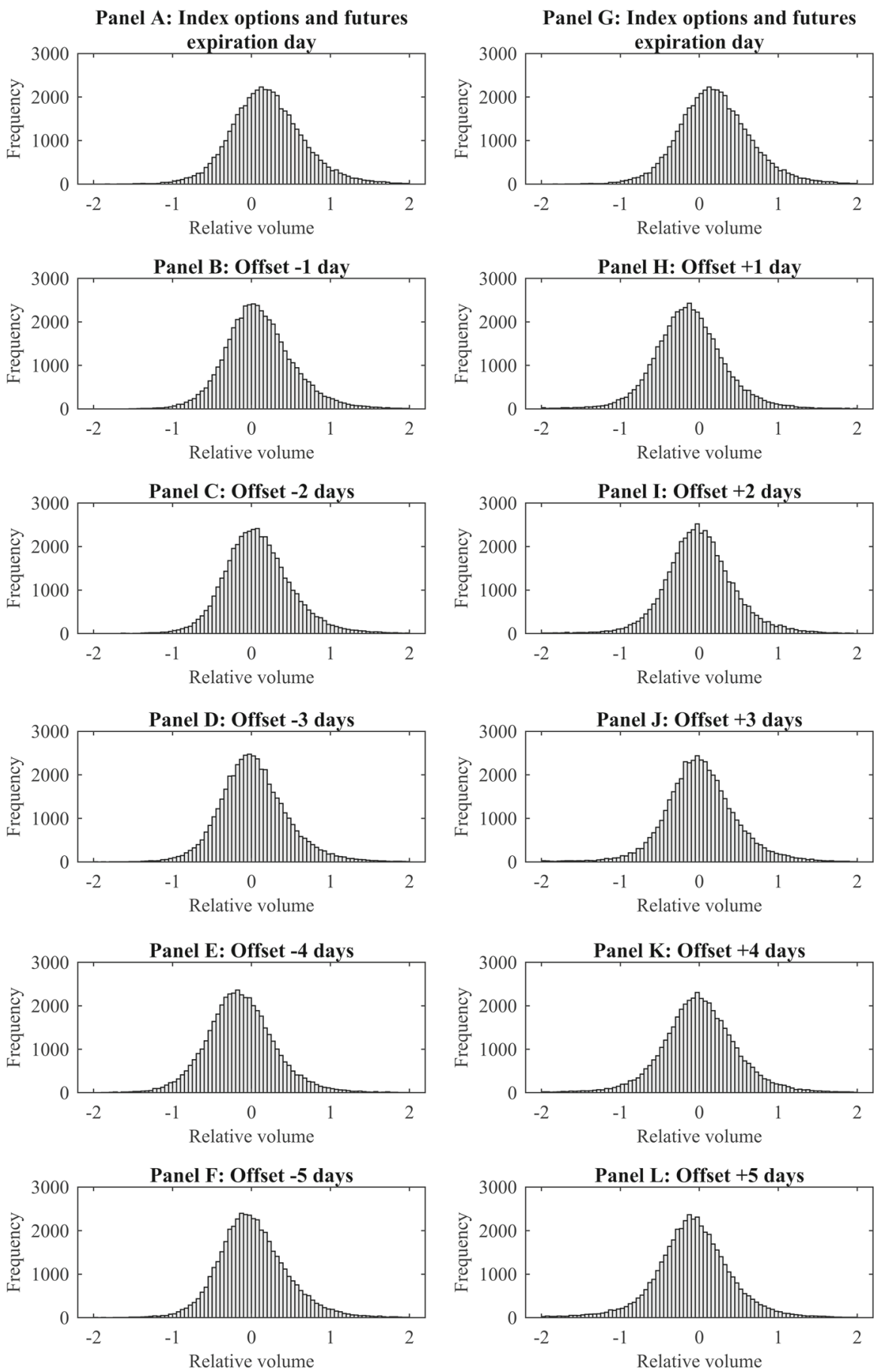

Fig. 7 Relative volume distribution for positive target date offsets (A-F) and negative target date offsets $(\mathbf{G}-\mathbf{L})$ relative to the index options and futures expiration days 

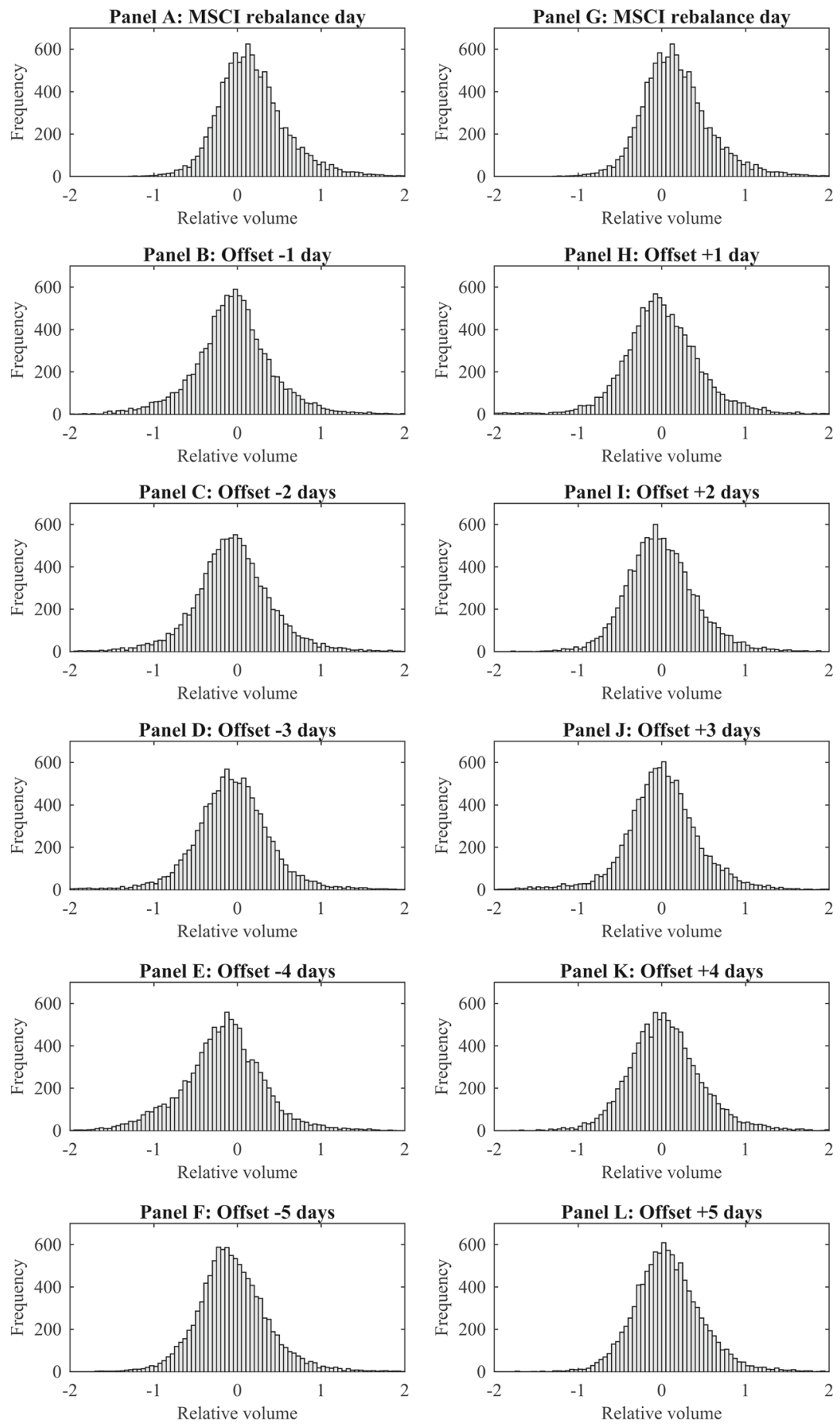

Fig. 8 Relative volume distribution for positive target date offsets $(\mathbf{A}-\mathbf{F})$ and negative target date offsets $(\mathbf{G}-\mathbf{L})$ relative to the MSCI rebalances 
Table 13 Comparison of the presence and absence of lagged volumes

Table 14 Comparison of the presence and absence of offsets

\begin{tabular}{llll}
\hline Model & Lagged volumes & Observations & CV MSE \\
\hline Expiration day & Yes & 45,912 & 0.17842 \\
& No & 45,912 & 0.22255 \\
MSCI rebalance & Yes & 10,298 & 0.14490 \\
& No & 10,298 & 0.17587 \\
\hline
\end{tabular}

\begin{tabular}{llll}
\hline Model & Target date offset & Observations & CV MSE \\
\hline Expiration day & Yes & 45,912 & 0.22495 \\
& No & 45,912 & 0.22255 \\
MSCI rebalance & Yes & 10,298 & 0.20140 \\
& No & 10,298 & 0.17587 \\
\hline
\end{tabular}

Next, we examine the results of the index expiration day and MSCI rebalance models and inspect a series of aspects regarding the coefficients and feature sets of these models.

\subsection{Volume autoregression}

Trading volume autoregression is constantly reported among the index expiration day and MSCI rebalance models. There is a significantly lower cross-validation MSE associated with the models fit with 20 lagged normalised volumes, as outlined in Table 13.

\subsection{Target date offset}

Fitting the observations for all the offsets that we considered (i.e. -5 trading days to +5 trading days, relative to the expiration/rebalance day) and including them into a model with 11-indicator variable for the target date offsets significantly increases the cross-validation MSE, which is reported in Table 14 for models fit with and without target date offsets.

Table 15 outlines the large volume associated with the expiration day and the 2 days prior to the expiration day in the reduced model for futures and options expiration day; there is a significantly positive correlation between trading volume and the MSCI rebalance day indicator. None of the days prior to or after the MSCI rebalance has any significance in terms of predicting the volumes. These coefficients represent the contribution of each feature to the trading volume and do not reflect the phenomenon documented in the previous randomisation tests, where the index options and futures expiration days are associated with high trading volumes from 4 days before the expiration day and until 2 days after the expiration day, and MSCI rebalances cause higher volumes on the day before the rebalance and on the rebalance effective date. 


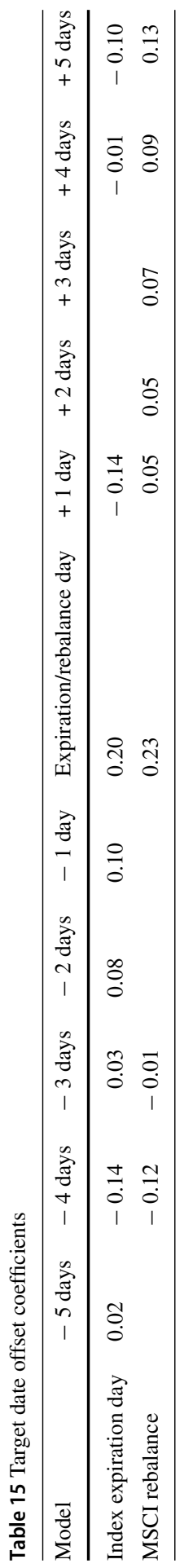


Based on the previous empirical findings, we fit a futures and options expiration day model and an MSCI rebalance model with 20 lagged normalised volumes and without offsets (i.e. considering only the index options and futures expiration days and the MSCI rebalances as target dates).

\subsection{Trading volume on stock index futures and options expiration days}

The regression coefficients for the reduced and full index expiration day models are summarised in Table 16, except for the coefficients for the 20 lagged normalised volumes. The 7 'expiration day index' predictors consist of indicator variables which are set to 1 if a given stock is the constituent of this index whose options and futures expiration day relative volume is the target variable. There is certainly strong multicollinearity, reflected by the zero coefficients of DAX and AEX in the full model. We conclude that we cannot discriminate between the expiration day indices of the stocks. Figure 9 illustrates the relative volume cumulative distribution on the target dates (i.e. the index options and futures expiration days) and on the control dates (i.e. dates with no expiration day, falling on the same day of the week as the index expiration day, with an offset up to 2 weeks relative to the expiration day) which were previously generated in the index expiration day randomisation test. We observe strong positive effects driven by the expiration day. DAX 30 exhibits conspicuous expiration day effects. The selected variables in the reduced model and the nearly zero-valued coefficients of AEX and IBEX in the full model are most probably caused by multicollinearity among the predictors.

\subsection{Trading volume on $\mathrm{MSCl}$ rebalance days}

Table 17 outlines the coefficient values for the 'trading country code' features for the MSCI rebalance reduced and full models. The models are trained with 20 lagged normalised volumes and no target date offsets (i.e. we only consider the MSCI quarterly review dates). The 'trading country' predictors are indicator variables denoting the exchange country of each stock that is part of the MSCI index constituent list. We argue that there is no clear discrimination by country of the effect magnitude of MSCI rebalance on the stock volume. The coefficients have high variability between the reduced and full models, which is likely caused by multicollinearity (e.g. Italy's and Sweden's coefficients are zero-valued in the full model, while they experience a great increase in the reduced model). The MSCI rebalance randomisation test performed in the Randomisation Analysis section provides evidence of a significantly greater trading volume on MSCI rebalances.

\subsection{Multi-step ahead analysis}

Multi-step ahead predictions are proposed besides the standard one-step ahead prediction, in order to allow traders to plan their portfolios by predicting an expiration day effect on a stock's trading volume. A common use case of multi-step ahead pre- 


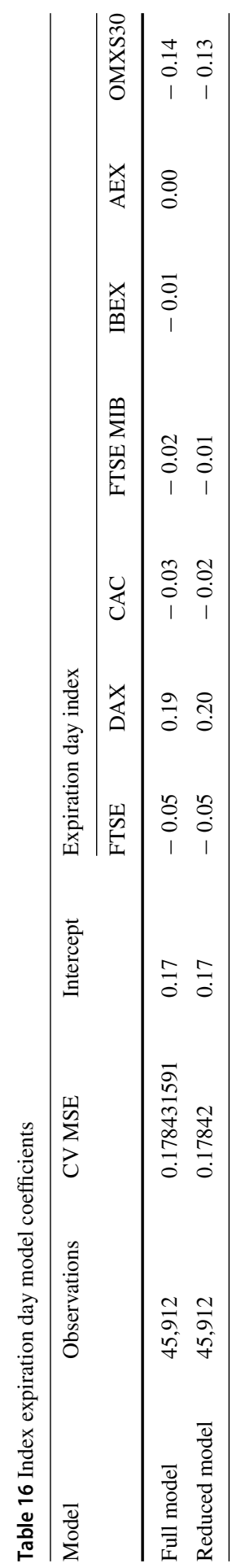



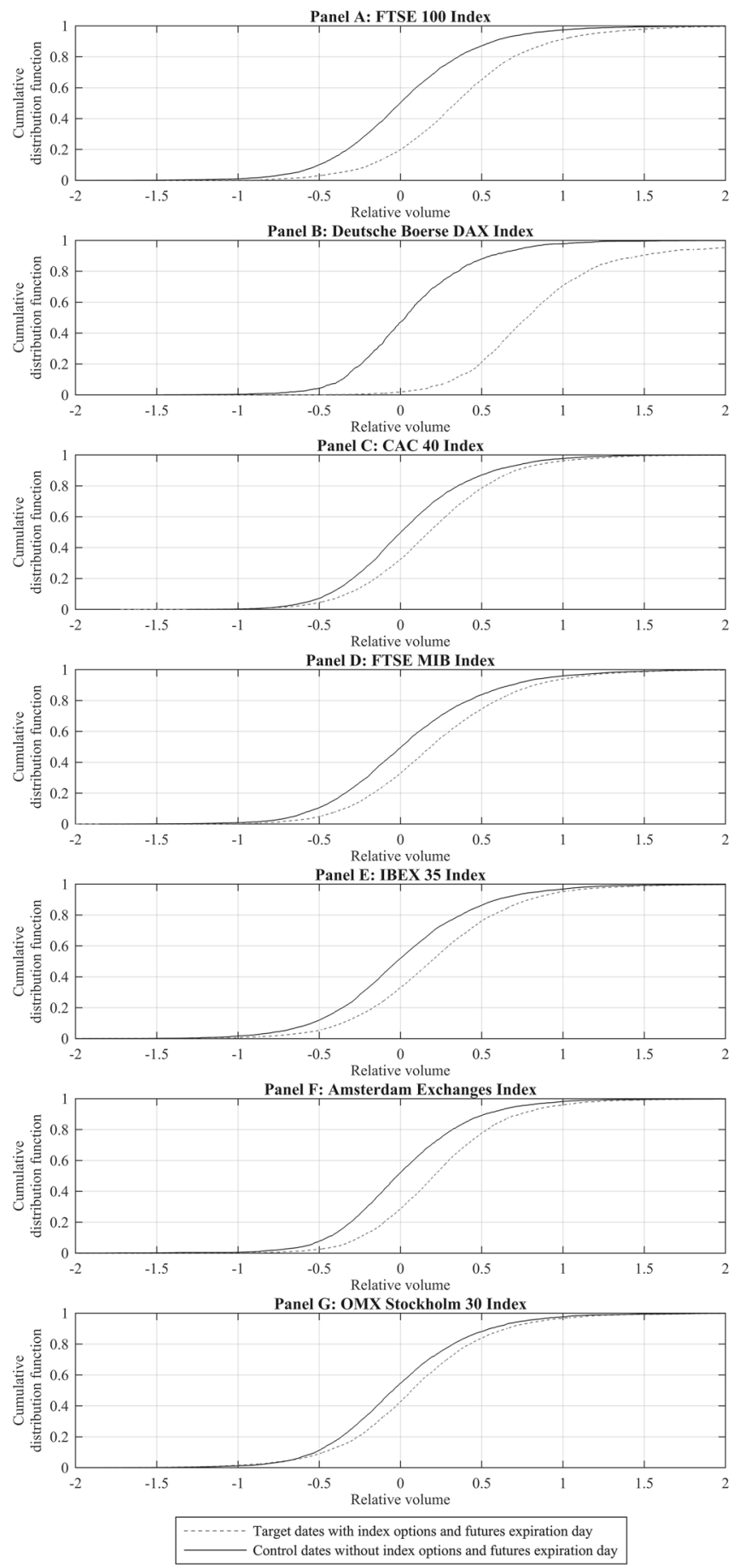

Fig. 9 Relative volume cumulative distribution for the target and control dates for the expiration day of each stock index analysed 


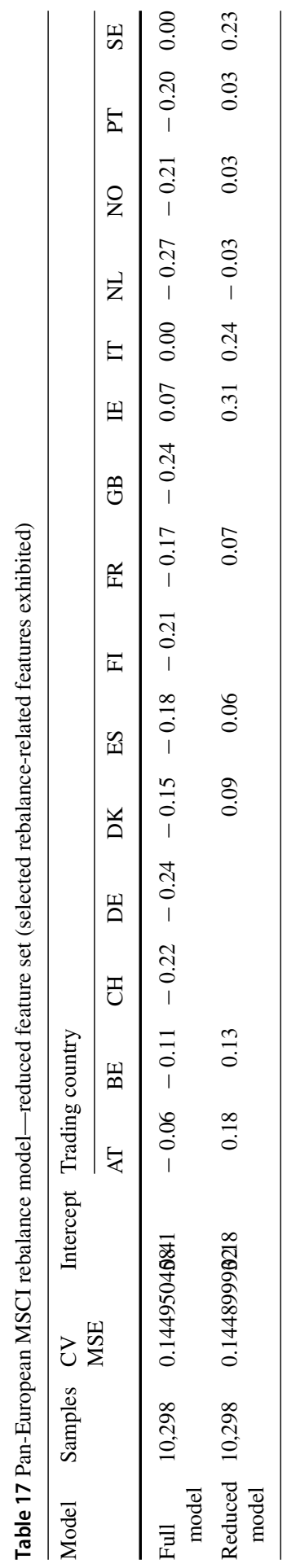


Table 18 Comparison of the cross-validation MSE between 1-step ahead and multi-step ahead reduced models

\begin{tabular}{lllllll}
\hline Model name & 1-step ahead & \multicolumn{5}{l}{ Multi-step ahead } \\
\cline { 3 - 7 } & & 2 & 3 & 4 & 5 & 6 \\
\hline Index expiration day & 0.17842 & 0.20623 & 0.21552 & 0.22359 & 0.23179 & 0.23780 \\
MSCI rebalance & 0.14490 & 0.16417 & 0.17407 & 0.17671 & 0.17879 & 0.18616 \\
\hline
\end{tabular}

diction for trading volume consists of traders and portfolio managers wanting to size a multi-day order allocation with the aim of minimising the market impact based on the available liquidity. One of the questions they could ask is how the trading volume would be throughout the next days, knowing that the options or futures on the index including a given stock expire in a few days' time. Traders and portfolio managers need to be able to quantify and forecast the volume trends in order to plan multi-day trades. This practical problem has not yet been addressed properly.

Supposing one wants to predict the impact of the expiration day effect on volume in $n$ days' time, then one computes the benchmark volume between $(t-n)$ and $(t-20-n)$ and compares it against the volume on the expiration/rebalance day (i.e. $V_{0}$ ) in order to train the model. All the $n$-step ahead expiration/review day models are fit for each step size $n$, between 1 day and 6 days, and dimensionality reduction is performed on these full models.

The multi-step ahead models perform similarly to the 1-step ahead analysis, for $n$ ranging from 2 to 6 . Their reduced models have similar feature sets to the 1-step ahead analysis. The cross-validation MSE is directly proportional with the step size and there is a constant trend of increasing the MSE as the prediction step ahead lag grows, as described in Table 18.

\section{Discussion}

The empirical evidence provided by this study supports a futures and options expiration day effect and an MSCI rebalance effect, corresponding to an increase in trading volume for the constituents of these indices on the index options and futures expiration days and the MSCI quarterly reviews, respectively. The expiration day effect could be caused either by the stock index futures and options roll forwards or by hedge rebalancing. The study investigates the European equity markets using a comprehensive pan-European stock universe of almost 500 stocks, with 45,912 observations for the stock index futures and options expiration day analysis, and 10,298 observations for the MSCI rebalance analysis that span almost 16 years. This study complements the existing literature by providing a pan-European empirical study for the expiration day effect on liquidity. We first explore the relationship between trading volume and the analysed periodic events, we then examine the existence of the expiration day effect, and finally propose a predictive model. The randomisation tests are an instance of the methodological rigour of this study, while fitting a number of models by apply- 
ing stepwise regression represents a methodological novelty in finance, besides the traditional OLS model fitting.

Trading activity surges on the expiration days of stock index futures and options. The volumes exhibit statistically significantly higher volumes relative to their pairwise control dates. A similar spike in trading volume is observed on the MSCI rebalance effective date, with statistically significantly higher volumes compared to their pairwise control dates. This study confirms that equity markets are in a rather steady state, but the market dynamics differ on some periodic notable events, which have been investigated in this study in order to document the temporal factors driving trading volume. The results are validated by the initial randomisation tests and the large European data universe.

We investigate whether it is the Friday effect or the Friday futures and options expiration day that drives the trading volume up and we provide evidence of a strong index options and futures expiration day effect. Furthermore, we analyse whether the MSCI rebalances can explain the end-of-month larger volumes; however, we conclude that the magnitude of the MSCI quarterly reviews is not sufficient to cause a generalised increase in volumes at the end of the month throughout the year. There is a potential end-of-month effect itself, which is driven by various factors that are well-documented in the literature, e.g. buying pressure around the end of the month, standardisation of payments around the turn-of-the-month, or the release of major US macroeconomic news.

Trading volume constantly exhibits a significant autoregressive property among the index options and futures expiration day and MSCI rebalance models. The study comes to an end by proposing a multi-step ahead prediction framework, which could be adapted in the industry such that traders and hedge fund managers could anticipate an expiration day effect by planning their portfolio in advance based on the predicted trading activity.

Acknowledgements This research has been funded by the Engineering and Physical Sciences Research Council (EPSRC) UK.

Open Access This article is distributed under the terms of the Creative Commons Attribution 4.0 International License (http://creativecommons.org/licenses/by/4.0/), which permits unrestricted use, distribution, and reproduction in any medium, provided you give appropriate credit to the original author(s) and the source, provide a link to the Creative Commons license, and indicate if changes were made.

\section{References}

Agrawal A, Tandon K (1994) Anomalies or illusions? Evidence from stock markets in eighteen countries. J Int Money Finance 13(1):83-106

Ariel RA (1987) A monthly effect in stock returns. J Financ Econ 18(1):161-184

Assogbavi T, Osagie JE (2006) Equity valuation process and price-volume relationship on emerging markets. Int Bus Econ Res J 5(9):7-18

Avellaneda M, Lipkin M (2003) A market-induced mechanism for stock pinning. Quant Finance 3:417-425 Barone E (1990) The Italian stock market: efficiency and calendar anomalies. J Bank Finance 14:483-510 Booth G, Kallunki J-P, Martikainen T (2001) Liquidity and the turn-of-the-month effect: evidence from Finland. J Int Financ Mark Inst Money 11(2):137-146 
Cadsby CB, Ratner M (1992) Turn-of-month and pre-holiday effects on stock returns: some international evidence. J Bank Finance 16(3):497-509

CBOE (2015) Stock index options. Retrieved from CBOE http://www.cboe.com/products/stock-indexoptions-spx-rut-msci-ftse. Accessed 12 Jun 2018

Chakrabarti R, Huang W, Jayaraman N, Lee J (2005) Price and volume effects of changes in MSCI indicesnature and causes. J Bank Finance 29(5):1237-1264

Chiang C-H (2009) Trading volume, returns and option expiration date. Columbia University, New York

Chicago Board Options Exchange (1975) Analysis of volume and price patterns in stocks underlying CBOE options from December 30, 1974 to April 30, 1975. Chicago Board Options Exchange, Chicago

Chow Y-F, Yung HH, Zhang H (2003) Expiration day effects: the case of Hong Kong. J Futures Mark 23(1):67-86

CME Group (2013) Understanding stock index futures. CME Group, Financial Research \& Product Development, Chicago

Cross F (1973) The behavior of stock prices on fridays and mondays. Financ Anal J 29(6):67-69

Dimson E, Marsh P (1999) Murphy's law and market anomalies. J Portf Manag 25(2):53-69

French KR (1980) Stock returns and the weekend effect. J Financ Econ 8(1):55-69

Gibbons MR, Hess P (1981) Day of the week effects and asset returns. J Bus 54(4):579-596

Golez B, Jackwerth JC (2012) Pinning in the S\&P 500 futures. J Financ Econ 106(3):566-585

Hansen PR, Lunde A, Nason JM (2005) Testing the significance of calendar effects. Working paper, Federal Reserve Bank of Atlanta, p 2005

Harris M, Raviv A (1993) Differences of opinion make a horse race. Rev Financ Stud 6(3):473-506

Hong H, Stein JC (2007) Disagreement and the stock market. J Econ Perspect 21(2):109-128

Hull JC (2002) Options, futures and other derivatives, 5th edn. Prentice Hall, New Jersey

Jaffe J, Westerfield R (1985) The week-end effect in common stock returns: the international evidence. J Finance 40(2):433-454

Karpoff JM (1987) The relation between price changes and trading volume: a survey. J Financ Quant Anal 22(1):109-126

Kunkel RA, Compton WS, Beyer S (2003) The turn-of-the-month effect still lives: the international evidence. Int Rev Financ Anal 12(2):207-221

Lakonishok J, Smidt S (1988) Are seasonal anomalies real? A ninety-year perspective. Rev Financ Stud 1(4):403-425

Martikainen T, Perttunen J, Puttonen V (1995) Finnish turn-of-the-month effects: return, volume, and implied volatility. J Futures Mark 15(6):605-615

Mills TC, Coutts AJ (1995) Calendar effects in the London stock exchange FT-SE indices. Eur J Finance 1(1):79-93

MSCI (2014) MSCI completes February 2014 ASR agreement. Retrieved 27 Oct 2015, from http://ir.msci. com/releasedetail.cfm?releaseid $=847313$

MSCI (2015) MSCI equity indexes August 2015 index review. Retrieved 27 Oct 2015, from https://www. msci.com/eqb/pressreleases/archive/MSCI_Aug15_QIRPR.pdf

Ni SX, Pearson ND, Poteshman AM (2005) Stock price clustering on option expiration dates. J Financ Econ 78(1):49-87

Nikkinen J, Sahlström P, Takko K, Äijö J (2009) Turn-of-the-month and intramonth anomalies and U.S. macroeconomic news announcements on the thinly traded finnish stock market. Int J Econ Finance $1(2): 3-11$

Ogden JP (1990) Turn-of-month evaluations of liquid profits and stock returns: a common explanation for the monthly and January effects. J Finance 45(4):1259-1272

Pearce DK (1996) The robustness of calendar anomalies in daily stock returns. J Econ Finance 20(3):69-80

Pettengill GN (2003) A survey of the Monday effect literature. Q J Bus Econ 42(3):3-27

Pope PF, Yadav PK (1992) The impact of option expiration on underlying stocks: the UK evidence. J Bus Finance Account 19(3):329-344

Rosenberg M (2004) The monthly effect in stock returns and conditional heteroscedasticity. Am Econ 48(2):67-73

Sadath A, Kamaiah B (2011) Expiration effects of stock futures on the price and volume of underlying stocks: evidence from India. IUP J Appl Econ 10(3):25-38

Schwert WG (2003) Chapter 15: anomalies and market efficiency. In: Constantinides G, Harris M, Stulz RM (eds) Handbook of the economics of finance. Elsevier B.V., Amsterdam, pp 937-972 
Stoll HR, Whaley RE (1997) Expiration-day effects of the all ordinaries share price index futures: empirical evidence and alternative settlement procedures. Aust J Manag 22(2):139-174

Sukumar N, Cimino A (2012) European trading volumes rise before last options expiry. Retrieved 19 May 2014, from Bloomberg http://www.bloomberg.com/news/2012-12-18/european-tradingvolumes-rise-before-last-options-expiry.html

Sullivan R, Timmermann A, White H (2001) Dangers of data mining: the case of calendar effects in stock returns. J Econ 105(1):249-286

The Trade (2007) Understanding index front running. The trade. Retrieved from http://www.thetradenews. com/magazine/The_TRADE_Magazine/2007/December/Understanding_index_front_running.aspx. Accessed 19 May 2016

Vipul (2005) Futures and options expiration-day effects: the Indian evidence. J Futures Mark 25(11):1045-1065

Publisher's Note Springer Nature remains neutral with regard to jurisdictional claims in published maps and institutional affiliations. 